\title{
Expression analysis of zinc transporters in resting and stimulated human peripheral blood mononuclear cells
}

\author{
THOMAS WEX ${ }^{1,3^{*}}$, KURT GRUNGREIFF $^{2 *}$, KERSTIN SCHUTTE $^{3}$, MAREN STENGRITT $^{3}$ and DIRK REINHOLD ${ }^{4}$ \\ ${ }^{1}$ Medical Laboratory for Clinical Chemistry, Microbiology and Infectious Diseases, Department of Molecular \\ Genetics; ${ }^{2}$ Practice of Hepatology; ${ }^{3}$ Department of Gastroenterology, Hepatology and Infectious Diseases; ${ }^{4}$ Institute \\ of Molecular and Clinical Immunology, Otto von Guericke University, D-39120 Magdeburg, Germany
}

Received July 04, 2013; Accepted January 07, 2014

DOI: $10.3892 /$ br.2014.219

\begin{abstract}
Intracellular zinc homeostasis is tightly regulated under physiological conditions; however, dysregulation of zinc levels has been reported in various chronic inflammatory and malignant diseases. In this study, we aimed to assess the expression pattern of the 24 currently known zinc transporters in resting and stimulated human peripheral blood mononuclear cells (PBMCs). The cells were isolated from healthy probands and subsequently stimulated with phytohaemagglutinin (PHA) for 3 days. The expression levels of zinc transporters [Zrt/IRT-like protein (ZIP) and cation diffusion facilitator/zinc transporter protein $(\mathrm{CDF} / \mathrm{ZnT})$ families] were analyzed by quantitative reverse transcription-polymerase chain reaction. Of the 24 genes encoding for zinc transporters, 19 were found to be ubiquitously expressed in PBMCs. ZIP5 and ZnT10 were not found in all 5 samples, whereas ZIP12, ZnT3 and ZIP2 were expressed in only 1-2 out of 5 PBMC samples. Of note, stimulation by PHA led to an overall downregulation of zinc transporters in the PBMCs of 4 out of the 5 subjects. Notably, the transcript levels of ZIP14 were consistently induced and those of ZIP3 and ZIP4 consistently downregulated in all 5 subjects, whereas the corresponding levels of the remaining 21 genes varied. Data from this study may facilitate a better understanding of the pathophysiological role of deregulated zinc transporters in chronic inflammatory diseases.
\end{abstract}

\section{Introduction}

Zinc is the most abundant trace element in human cells and is involved in numerous catalytic, structural and regulatory

Correspondence to: Professor Thomas Wex, Medical Laboratory for Clinical Chemistry, Microbiology and Infectious Diseases, Department of Molecular Genetics, Am Neustadter Feld 47, Otto von Guericke University, D-39124 Magdeburg, Germany

E-mail: t.wex@schenk-ansorge.de

*Contributed equally

Key words: zinc transporter, peripheral blood cells, zinc transporter protein, Zrt-Irt-like protein, quantitative polymerase chain reaction processes (1). As an essential component of $>150$ different enzymes, zinc plays an essential role in gene expression, cell differentiation, proliferation and signal transduction (2-5).Zinc was recently identified as an intracellular signaling molecule in immune cells, affecting cytokine production, apoptosis and T-cell proliferation (6-10), suggesting that intracellular zinc homeostasis is indispensable for an adequate immune response (2).

The liver plays an important role in maintaining zinc homeostasis by regulating extracellular zinc levels following its primary absorption by enterocytes (11-13). Various hormones, such as insulin, glucagon and glucocorticoids and cytokines, such as IL-6, are involved in this regulation $(4,14,15)$.

At the cellular level, zinc homeostasis is considered to be tightly regulated by 14 members of the Zrt/IRT-like protein (ZIP) and 10 members of the zinc transporter protein (ZnT) families of export/efflux proteins (16-19).

Over the last decades, epidemiological studies have associated reduced plasma/serum zinc levels with numerous medical conditions, such as diarrhea, pneumonia, diabetes mellitus, sickle cell anemia, cancer, impaired function of the immune system, gastrointestinal and chronic liver diseases and cancer (11,20-22).

In line with the pathophysiological significance of zinc as a trace element and the presence of specific ZnT and ZIP transporters, it is not surprising that a deregulation of some of these transporters has been described in the context of various diseases. Notably, there are few examples of a causal association between up- or downregulated zinc transporters and pathological conditions; ZnT8 appears to be causally involved in the development and/or progression of diabetes mellitus, although the underlying mechanism is disputed over. Chimienti et al (23) suggested that the reduced ZnT8 expression may result in impaired insulin storage and secretion by a reducing intracellular zinc pool. Other studies identified the presentation of ZnT8-derived peptides by HLA-A*0201-restricted T cells, leading to autoimmune disease and the subsequent development of diabetes type $1(24,25)$. An ex vivo analysis of breast cancer tissue revealed abnormal expression of multiple proteins that are involved in zinc homeostasis, including ZIP6, ZIP7, ZIP10 and ZIP12 (26), whereas ZIP4 was found to be upregulated in pancreatic cancer (24). In hepatocellular carcinoma, the downregulation of ZIP14 was 
considered to be critically involved in the reduction of cellular zinc levels in the hepatocytes of patients with chronic liver damage (27-29).

Taking into consideration that chronic inflammatory diseases are regulated by immune cells and the various studies suggesting a regulatory role of zinc levels for the activity of these cells, our study aimed to investigate the overall expression pattern of the 24 currently known zinc transporters in resting and mitogen-stimulated peripheral blood immune cells.

\section{Materials and methods}

Isolation of peripheral blood mononuclear cells (PBMCs) and mitogen-induced stimulation. PBMCs were isolated from the heparinized venous blood of 5 healthy donors by density gradient centrifugation over Ficoll gradients (Biochrom, Berlin, Germany), as previously described (30). The cells were suspended in serum-free AIM-V culture medium (Invitrogen, Eggenstein, Germany) and incubated in the presence and absence of phytohaemagglutinin (PHA) $(1 \mu \mathrm{g} / \mathrm{ml}$; Sigma, Taufkirchen, Germany) for $72 \mathrm{~h}$ at $37^{\circ} \mathrm{C}$.

No further clinical information or laboratory parameters (e.g., zinc serum levels or number and composition of immune cell population) were available.

Extraction of total RNA and quantitative reverse transcription-polymerase chain reaction ( $q R T-P C R)$. Total RNA from 107 PBMCs was extracted using the RNeasy kit (Qiagen, Hilden, Germany) according to the manufacturer's instruction. Finally, the RNA was eluted in $70 \mu \mathrm{l}$ RNase-free water. Aliquots of $5 \mu 1$ each were used for the determination of RNA concentration via UV-spectroscopy and for the evaluation of RNA integrity by agarose gel electrophoresis. In each case, 500 ng of total RNA was transcribed into cDNA in a 40- $\mu 1$ reaction volume by AMV reverse transcriptase (Promega, Mannheim, Germany) and random hexanucleotides (Boehringer, Mannheim, Germany) using a standard protocol as previously described (31).

The transcript levels of the 24 zinc transporters and $\beta$-actin were determined by qRT-PCR using the FX96 Cycler (Bio-Rad, Munich, Germany) and the QuantiTect ${ }^{\mathrm{TM}}$ SYBR-Green kit (Qiagen), using $1.5 \mu \mathrm{l} \mathrm{cDNA}$ and primer sets under the standard conditions described in Table I. The initial template mRNA amounts for all the genes were calculated using $\mathrm{Ct}$-values as determined by the iCycler software in two steps as described below. Due to the primer design (usage of intron-spanning regions), the amplification of genomic DNA was excluded. Therefore, the gene expression levels [arbitrary units (a.u.)] illustrate the mRNA pool of the individual gene investigated. Randomly selected amplification products for each of the 25 primer sets were checked for their correct size by agarose gel electrophoresis in the context of melting curve analysis, ensuring specificity of the PCR products for all the reactions.

Data presentation, calculation of transcript levels and statistics. All the data were entered into a database using the Microcal Origin ${ }^{\mathrm{TM}} 8.0$ program package (OriginLab Corporation, Northhampton, MA, USA). Data are expressed as median and 95\% confidence intervals (CIs) unless otherwise stated. The calculation of the transcript levels was performed as follows: First, the transcript levels of the 24 zinc transporters in resting PBMCs were normalized to the $\beta$-actin level of the corresponding sample. These results are expressed as a.u. and represent the ratios between the investigated gene and $\beta$-actin transcript amounts. Second, in order to illustrate the changes of zinc transporter transcript levels following PHA-induced stimulation, the normalized transcript levels of the stimulated sample were divided by the corresponding data of the non-stimulated control. These data represent an $\mathrm{x}$-fold change following stimulation based on medians for each gene (stimulated vs. non-stimulated). Of note, in order to illustrate an upregulation of zinc transporters not expressed under basal conditions, i.e., ZnT10 and ZIP5, samples with missing expression were arbitrarily assigned to cycle 45 and then normalized to the corresponding $\beta$-actin transcript level of the identical sample. Therefore, the $\mathrm{x}$-fold changes of all the samples for ZnT10, ZIP5 and, in part, ZIP12 (4 samples), ZnT3 (4 samples) and ZIP2 (2 samples) genes represent 'artificial values' determined by the arbitrary transcript level of the non-stimulated sample.

Due to the explorative nature of this study, data are described without statistical assessment.

\section{Results}

Expression of zinc transporters. The amplified PCR products revealed the correct size of the expected cDNA fragment for all the PCR assays (data not shown). Of the 24 zinc transporters, 19 were found to be ubiquitously expressed in all 5 non-stimulated PBMC samples (Fig. 1). In general, the variability within one gene was within 1-2 orders of magnitude. The median transcript levels of these 19 genes varied by less than 2 orders of magnitude. Individual expression levels among the 19 genes varied by 4 orders of magnitude. ZIP5 and ZnT10 (5x negative), ZIP12 and ZnT3 (4x negative) and ZIP2 (2x negative) were not expressed or only detected in a limited number of samples (Fig. 1).

PHA stimulation. The stimulation of PBMCs by PHA led to a general proliferative stimulation of these cells (data not shown). In order to normalize for the interindividual differences among probands, the expression levels of the stimulated cells were normalized to the basal expression of the corresponding sample. As demonstrated in Fig. 2, only 4 genes exhibited a consistent expression pattern among the 5 PBMC samples. ZIP14 was found to be induced (1.2- to 27-fold), whereas the expression of ZIP3, ZIP4 and ZIP13 was decreased in all 5 PBMC samples. The remaining 21 zinc transporter genes were differentially expressed among the 5 stimulated PBMC samples. In addition to ZIP14, ZIP5 and ZnT3 were found to be induced by 12- and 15 -fold (based on medians), respectively, whereas the transcript levels of other zinc transporter genes were found to be reduced or unchanged (Fig. 2). Of note, several samples of stimulated PBMCs [ZIP2 (1x), ZIP5 and ZIP13 (2x), ZIP12 (4x) and ZnT10 $(5 \mathrm{x})]$ were not found to be expressed.

Analysis of variability. An analysis of the variability among the 5 probands revealed a similar expression pattern for 4 of the 5 PBMC samples (Table II). The PBMCs of proband no. 2 , in particular, exhibited a different pattern, with 15 induced zinc 
Table I. Primer sets for qRT-PCR.

\begin{tabular}{|c|c|c|c|}
\hline Gene/accession number & Name & Sequence of primers & $\begin{array}{l}\text { Size of the PCR } \\
\text { product (bp) }\end{array}$ \\
\hline ZnT1 (SLC30A1)/NM_021194 & $\mathrm{ZnT1}$ & $\begin{array}{l}\text { F: 5'-CCAACACCCTGGTGGCCAATAC-3' } \\
\text { R: 5'-TGAACCCAAGGCATCTCCAAGG-3' }\end{array}$ & 212 \\
\hline ZnT2 (SLC30A2)/NM_001004434 & $\mathrm{ZnT} 2$ & $\begin{array}{l}\text { F: 5'-CTGCGCTGTGGCTGTGAACATC-3' } \\
\text { R: 5'-TCCACCGACAGCAGCAGATCAC-3' }\end{array}$ & 345 \\
\hline ZnT3 (SLC30A3)/NM_003459 & $\mathrm{ZnT3}$ & $\begin{array}{l}\text { F: 5'-CACTGGCATCCTCCTGTACCTG-3' } \\
\text { R: 5'-GGTCGGCTGCCTTGTATTGAG-3' }\end{array}$ & 332 \\
\hline ZnT4 (SLC30A4)/NM_013309 & $\mathrm{ZnT} 4$ & $\begin{array}{l}\text { F: 5'-GCGCCATCATACTCACCCTG-3' } \\
\text { R: 5'-GTGACGGTGACCAGACTGGTTC-3' }\end{array}$ & 275 \\
\hline ZnT5 (SLC30A5)/NM_022902 & $\mathrm{ZnT5}$ & $\begin{array}{l}\text { F: 5'-TTAAACATGCAGTTGCTGGGTG-3' } \\
\text { R: 5'-ACCCTTGTGATCTGCCACACC-3' }\end{array}$ & 329 \\
\hline ZnT6 (SLC30A6)/NM_001193513 & ZnT6 & $\begin{array}{l}\text { F: 5'-TTTGGAACAGCCCGAGATACAC-3' } \\
\text { R: 5'-AAAGAGCAAATGCTCCAGCAAG-3' }\end{array}$ & 260 \\
\hline ZnT7 (SLC30A7)/NM_133496 & $\mathrm{ZnT7}$ & $\begin{array}{l}\text { F: 5'-GGAAGTTCTGGCTGGCTTTGTC-3' } \\
\text { R: 5'-GGCTATGGCAATGATCGACATG-3' }\end{array}$ & 278 \\
\hline ZnT8 (MADD)/NM_130470 & ZnT8 & $\begin{array}{l}\text { F: 5'-TGCCTTTCAGCGAATTCACAAC-3' } \\
\text { R: 5'-GTGCTGCATGTGTCAGAGGGTC-3' }\end{array}$ & 311 \\
\hline ZnT9 (SLC30A9)/NM_006345 & ZnT9 & $\begin{array}{l}\text { F: 5'-AAATACCAAGCCACGCTCCAG-3' } \\
\text { R: 5'-TGCCCAATGCTAGTAAACCCTG-3' }\end{array}$ & 200 \\
\hline ZnT10 (SLC30A10)/NM_018713 & $\mathrm{ZnT} 10$ & $\begin{array}{l}\text { F: 5'-GACCGTGTTCGCAAACGTAGC-3' } \\
\text { R: 5'-TTGATAAGCGGGAAGGCAGATG-3' }\end{array}$ & 282 \\
\hline ZIP1 (SLC39A1)/NM_014437 & ZIP1 & $\begin{array}{l}\text { F: 5'-CGGCCAGGAGCTAACCATGAAG-3' } \\
\text { R: 5'-GCCCACCATTCACTGTTCCCAG-3' }\end{array}$ & 307 \\
\hline ZIP2 (SLC39A2)/NM_014579 & ZIP2 & $\begin{array}{l}\text { F: 5'-ACTCTGGGCTGTGGCCTTACTC-3' } \\
\text { R: 5'-AAGCCCAGGGAGATGATGAGC-3' }\end{array}$ & 284 \\
\hline ZIP3 (SLC39A3)/NM_213568 & ZIP3 & $\begin{array}{l}\text { F: 5'-TGGTTGGGCTCGGTAGCACATC-3' } \\
\text { R: 5'-GTCACTGCAGGGCCAAACCATC-3' }\end{array}$ & 68 \\
\hline ZIP4 (SLC39A4)/NM_017767 & ZIP4 & $\begin{array}{l}\text { F: 5'-CAACAGCTCCAGTGTGTGGGAC-3' } \\
\text { R: 5'-GCTCAGGAAGGTCTGCAGGATG-3' }\end{array}$ & 319 \\
\hline ZIP5 (SLC39A5)/NM_173596 & ZIP5 & $\begin{array}{l}\text { F: 5'-TCATTGGCTGACCACCTGAATG-3' } \\
\text { R: 5'-AGCAAGGGCCGTAGTAGACGAG-3' }\end{array}$ & 293 \\
\hline ZIP6 (SLC39A6)/NM_012319 & ZIP6 & $\begin{array}{l}\text { F: 5'-CATGGCATGGGCATCCAGGTTC-3' } \\
\text { R: 5'-TCAAAGTCCCAACGGCCAGTGC-3' }\end{array}$ & 289 \\
\hline ZIP7 (SLC39A7)/NM_006979 & ZIP7 & $\begin{array}{l}\text { F: 5'-CAGGACCTGGATGCTGTCACTC-3' } \\
\text { R: 5'-CGACAAGAAAGGCAACAATTCC-3' }\end{array}$ & 319 \\
\hline ZIP8 (SLC39A8)/NM_022154 & ZIP8 & $\begin{array}{l}\text { F: 5'-CTGCCATCAATGGTGTGACATG-3' } \\
\text { R: 5'-CCCTGAAGGAGAGACAAGGTGC-3' }\end{array}$ & 253 \\
\hline ZIP9 (SLC39A9)/NM_018375 & ZIP9 & $\begin{array}{l}\text { F: 5'-TGCTGGCCTTCTCTGTGGAAC-3' } \\
\text { R: 5'-TGCTAGACCTTGCTGCTTCTGG-3' }\end{array}$ & 302 \\
\hline ZIP10 (SLC39A10)/NM_001127257 & ZIP10 & $\begin{array}{l}\text { F: 5'-GCATAATCGGGTCCACAAACC-3' } \\
\text { R: 5'-AACAATGCAGGGCAAAGGTATG-3' }\end{array}$ & 318 \\
\hline ZIP11 (SLC39A11)/NM_001159770 & ZIP11 & $\begin{array}{l}\text { F: 5'-CGGCATCTGCTACCTTTGAGAG-3' } \\
\text { R: 5'-ATGATGTCGTCCATGACCACG-3' }\end{array}$ & 269 \\
\hline ZIP12 (SLC39A12)/NM_001145195 & ZIP12 & $\begin{array}{l}\text { F: 5'-CGAATACCCTCCGCCTATCAG-3' } \\
\text { R: 5'-TGCTGGATGATCCCTGGACTC-3' }\end{array}$ & 299 \\
\hline ZIP13 (SLC39A13)/NM_001128225 & ZIP13 & $\begin{array}{l}\text { F: 5'-CTCTTGGGCAATGTGTTTCTGC-3' } \\
\text { R: 5'-GACTTTGATGCTCCGGACCAC-3' }\end{array}$ & 300 \\
\hline ZIP14 (SLC39A14)/NM_001128431 & ZIP14 & $\begin{array}{l}\text { F: 5'-CTCTGTGTGACCGTCATCTCCC-3' } \\
\text { R: 5'-AAGCGACTCAGAGGCATAATGG-3' }\end{array}$ & 315 \\
\hline
\end{tabular}

Standard protocol: initial step at $95^{\circ} \mathrm{C}$ for $15 \mathrm{~min} ; 40$ cycles at $94^{\circ} \mathrm{C}$ for $30 \mathrm{sec}$, at $57^{\circ} \mathrm{C}$ for $30 \mathrm{sec}$ and at $72^{\circ} \mathrm{C}$ for $30 \mathrm{sec}$; and annealing at $72^{\circ} \mathrm{C}$ for 5 min. qRT-PCR, quantitative reverse transcription-polymerase chain reaction. 


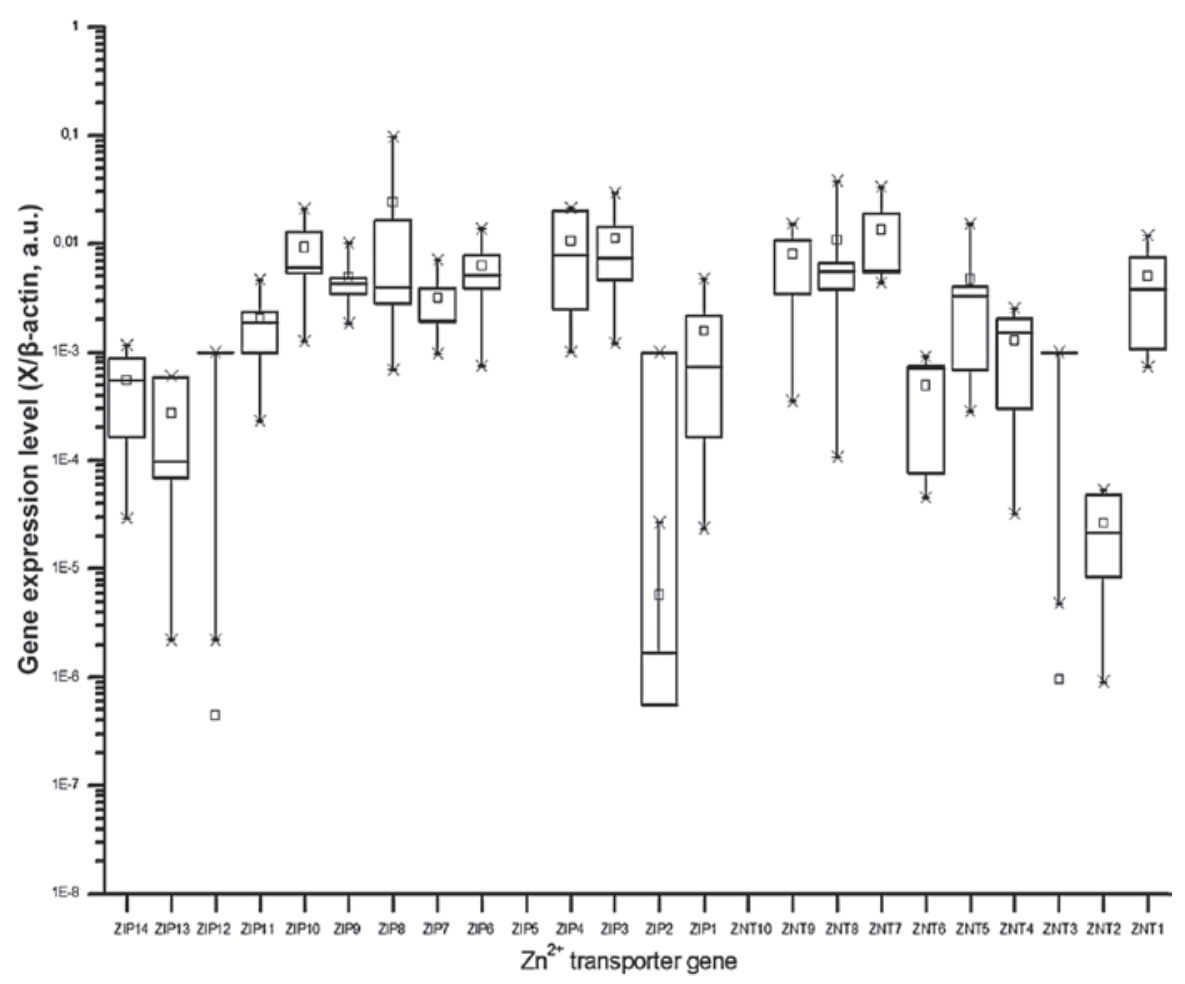

Figure 1. Expression of the 24 zinc transporter genes in non-stimulated peripheral blood mononuclear cells. Data are shown as boxplots representing 25,75 percentile, median and 5-95 range. The means are represented by the small square. The skewed distribution, particularly for the 5 genes with very low expression levels, is due to the presence of samples without any gene expression (see text 'Expression of zinc transporters'). Note: all 'negative samples' cannot be illustrated, due to the logarithmic scale of the y-axis. A.u., arbitrary units; $\mathrm{Zn}^{2+}$, zinc.

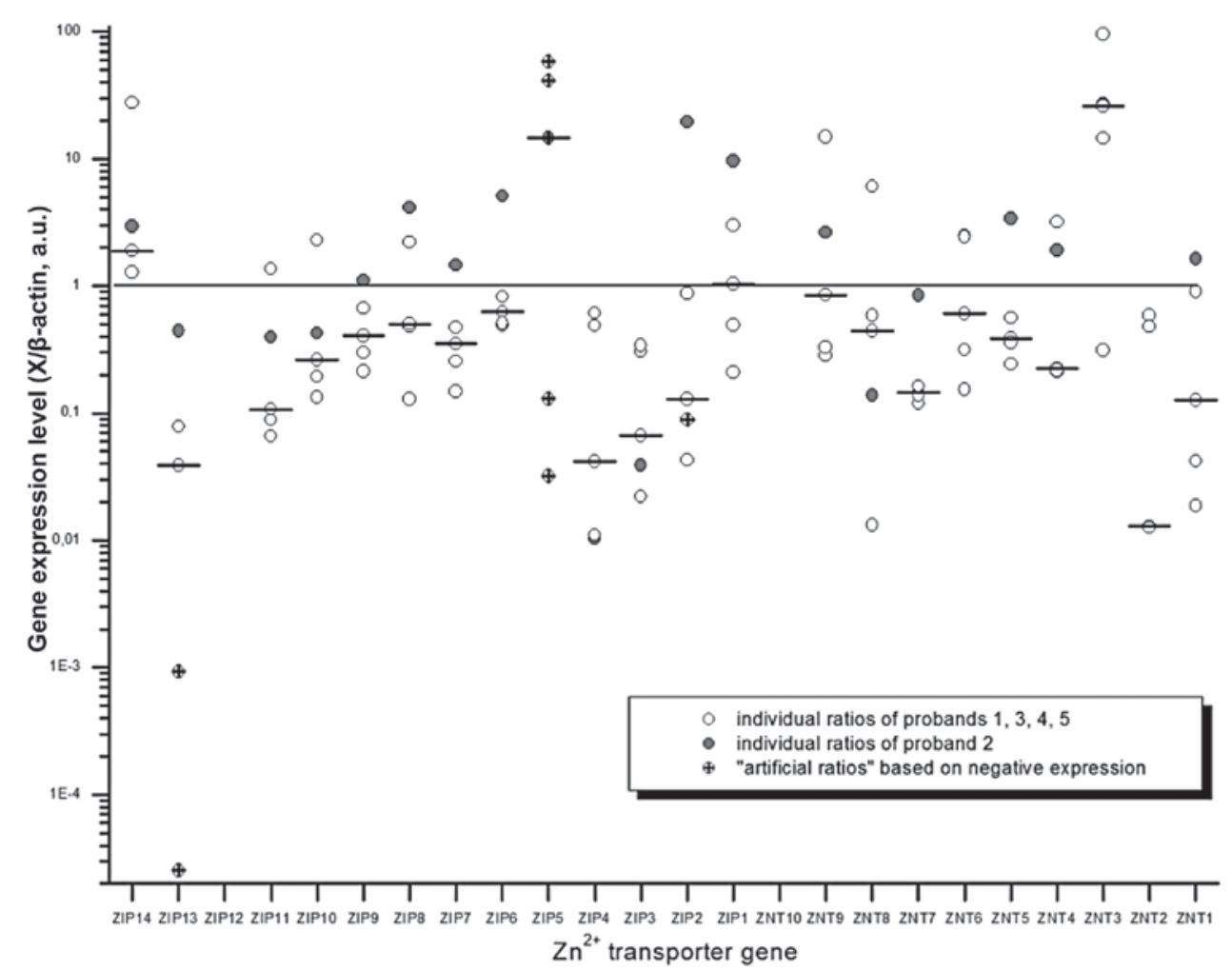

Figure 2. Expression of the 24 zinc transporter genes in stimulated peripheral blood mononuclear cells (PBMCs). The expression levels for the 24 zinc transporter genes were determined in stimulated PBMCs. These data were normalized to the level of the corresponding non-stimulated cells. The horizontal line illustrates factor 1 that showed no change between stimulated and non-stimulated PBMCs. Due to the variability among the 5 samples, data are shown as a histogram. The small circles illustrate individual experiments. Increased and decreased expression are represented by values $>1$ and $<1$, respectively. The small lines represent the median of the dataset. The samples of proband no. 2, which exhibited a different expression pattern, are represented by the gray circles. Note: all 'artificial values' (for details see 'Data presentation, calculation of transcript levels and statistics' for ZIP2, ZIP5, ZIP12, ZnT3 and ZnT10) are marked by a cross within the circle. Due to the similar extent of upregulation (e.g., ZIP14, 1.27-fold, 1.28-fold) all the ratios are not illustrated. A.u., arbitrary units; $\mathrm{Zn}^{2+}$, zinc. 
Table II. Qualitative change of zinc transporter gene expression patterns of individual samples.

\begin{tabular}{lcc}
\hline PBMC & $\begin{array}{c}\text { No. of induced zinc } \\
\text { transporter genes } \\
\text { sample no. }\end{array}$ & $\begin{array}{c}\text { No. of reduced zinc } \\
\text { transporter genes } \\
(\text { ratio }>1, \text { Fig. } 3)\end{array}$ \\
\hline
\end{tabular}

$\begin{array}{ccc}1 & 4 & 20 \\ 2 & 15 & 9 \\ 3 & 2 & 22 \\ 4 & 4 & 20 \\ 5 & 7 & 17\end{array}$

Absolute numbers represent the numbers of transporter genes either induced (ratio induced/control cells $>1$ ) or reduced (corresponding ratio $<1$ ) for the 24 genes. PBMC, peripheral blood mononuclear cell.

transporter genes; in the remaining 4 samples only 2-7 genes exhibited increased expression (Fig. 2).

\section{Discussion}

In this study, we demonstrated that i) the majority of zinc transporters are ubiquitously expressed in peripheral blood immune cells; ii) ZIP14, ZIP5 and ZnT3 are strongly induced following stimulation and during proliferative response; and iii) the gene expression of the majority of zinc transporters is downregulated following proliferative stimulation.

Several previous studies described the expression profiles and patterns for selected zinc transporters in different contexts.Giacconi etal (10) demonstrated the ubiquitous expression of ZIP1, ZIP2 and ZIP3 in non-adherent lymphocytes; however, younger individuals exhibited higher transcript levels compared to elderly subjects. Overbeck et al (32) assessed the expression of ZnT1-9 in various leukocyte subsets in regard to zinc depletion and proliferative response and the basal expression patterns of the $9 \mathrm{ZnT}$ transporters in PBMCs partially corresponded to our data. Similarly, ZnT2 and ZnT3 were not expressed or expressed to a very low extent, whereas ZnT1 was not the most dominant transporter in our study. Following PHA-induced proliferation in primary $\mathrm{T}$ cells, all $9 \mathrm{ZnT}$ transporters exhibited reduced expression patterns compared to the controls (32). A similar result was obtained in this study by demonstrating reduced transcript levels for all the ZnT genes, except for ZnT3. This difference may be attributed to the very low basal expression level in primary PBMCs and the potential induction of ZnT3 expression in immune cell types that were not investigated by Overbeck et al (32). In addition to peripheral PBMCs, the authors of that study analysed the expression of $\mathrm{ZnT}$ transporters in purified $\mathrm{T}$ and $\mathrm{B}$ cells and observed a very similar expression pattern between the two cell types (32). Taking into consideration that several dendritic subsets express various zinc transporters, such as ZIP2 in mice (33) and ZIP6 (34), it is tempting to hypothesize that the induction of ZnT3 by PHA in our study may result from a small subset of dendritic cells present in the PBMC samples from of our subjects. Thus far, ZnT3 has been primarily identified in nerve fibers in mice and humans $(35,36)$. Notably, the expression patterns were mainly similar in 4 of the 5 subjects. In line with the study of Overbeck et al (32), the majority of zinc transporters were downregulated following mitogenic stimulation. The opposite finding observed in subject no. 2 (15 of the 24 genes were upregulated) may be attributed to various factors. Technical reasons (quality of PBMCs or RNA) may be excluded, since the results of $\beta$-actin (analysed as housekeeping gene) were not different. Furthermore, the PCR assays for ZnT10 and ZIP5 (negative in all 5 samples) were validated using liver tissues in which the expected PCR products were detected. Whether the individual immunological status of subject no. 2 is the potential cause for the induction of zinc transporters following PHA stimulation, possibly due to the presence of subclinical infection or generally reduced zinc levels, remains unresolved, since neither clinical data nor additional ex vivo material (i.e., blood samples) of the subjects were available. The individual differences regarding the expression levels of the 24 genes among the 5 individuals may result from i) variations in the composition of peripheral PBMCs that were not further characterized; and ii) different serum zinc levels that regulate the expression levels of zinc transporters $(4,37)$.

The advantages of this study lie with the comprehensive analysis of gene expression levels of the 24 zinc transporters in peripheral blood immune cells, in resting state and following stimulation by PHA. In general, peripheral immune cells express a broad range of zinc transporters; however, the expression of the majority of these transporters is reduced following immunological stimulation. Due to the study design, we are unable to conclude on the expression of zinc transporters in various subsets of immune cells or its functional aspects. The acquired knowledge regarding the general expression pattern of zinc transporters in resting and stimulated peripheral immune cells may facilitate the identification of potential deregulated zinc transporters in chronic diseases.

\section{Acknowledgements}

We would like to thank Ursula Stolz, Marion Holley (Clinic of Gastroenterology) and Karina Guttek (Institute of Molecular and Clinical Immunology) for their contribution to this study.

\section{References}

1. Vallee BL and Falchuk KH: The biochemical basis of zinc physiology. Physiol Rev 73: 79-118, 1993.

2. Prasad AS: Zinc: role in immunity, oxidative stress and chronic inflammation. Curr Opin Clin Nutr Metab Care 12: 646-652, 2009.

3. Haase $\mathrm{H}$ and Rink L: Functional significance of zinc-related signaling pathways in immune cells. Annu Rev Nutr 29: 133-152, 2009.

4. Maret W: Human zinc biochemistry. In: Zinc in Human Health. Rink L (ed). IOS Press, Amsterdam, pp45-62, 2011.

5. Consolo M, Amoroso A, Spandidos DA and Mazzarino MC: Matrix metalloproteinases and their inhibitors as markers of inflammation and fibrosis in chronic liver disease (Review). Int J Mol Med 24: 143-152, 2009.

6. Hirano T, Murakami T, Fukada T, Nishida K, Yamasaki S and Suzuki T: Roles of zinc and zinc signaling in immunity: zinc as an intracellular signaling molecule. Adv Immunol 97: 149-176, 2008.

7. Haase H, Ober-Blobaum JL, Engelhardt G, Hebel S, Heit A, Heine $\mathrm{H}$ and Rink L: Zinc signals are essential for lipopolysaccharide-induced signal transdution in monocytes. J Immunol 181: 6491-6502, 2008. 
8. Kaltenberg J, Plum LM, Ober-Blobaum JL, Honscheid A, Rink L and Haase H: Zinc signals promote IL-2-dependent proliferation of T cells. Eur J Immunol 40: 1496-1503, 2010.

9. Yamaguchi M and Uchiyama S: Combination of $\beta$-cryptoxanthin and zinc has potent effects on apoptotic cell death and suppression of bone resorption-related gene expression in osteoclastic cells. Int J Mol Med 22: 221-228, 2008.

10. Giacconi R, Malavolta, Costarelli L, Busco F, Galeazzi R, Bernardini G, Gasparini N and Mocchegiani E: Comparison of intracellular zinc signals in nonadherent lymphocytes from young-adult and elderly donors: role of zinc transporters (Zip family) and proinflammatory cytokines. J Nutr Biochem 23: 1256-1263, 2012

11. Grungreiff K and Reinhold D: Zinc and the liver. In: Zinc in Human Health. Rink L (ed). IOS Press, Amsterdam, pp473-492, 2011.

12. Tuerk MJ and Fazel N: Zinc deficiency. Curr Opin Gastroenterol 25: 136-143, 2009.

13. Maret W: Molecular aspects of human cellular zinc homeostasis: redox control of zinc potentials and zinc signals. Biometals 22 149-157, 2009.

14. Etzel KR, Shapiro SG and Cousins RJ: Regulation of liver metallothionein and plasma zinc by the glucocorticoid dexamethasone. Biochem Biophys Res Commun 89: 1120-1126, 1979

15. Liuzzi JP, Lichten LA, Rivera S, Blanchard RK, Aydemir TB Knutson MD, Ganz T and Cousins RJ: Interleukin-6 regulates the zinc transporter Zip14 in liver and contributes to the hypozincemia of the acute-phase response. Proc Natl Acad Sci USA 102: 6843-6848, 2005.

16. Eide DJ: Zinc transporters and the cellular trafficking of zinc. Biochim Biophys Acta 1763: 711-722, 2006.

17. Lichten LA and Cousins RJ: Mammalian zinc transporters: nutritional and physiologic regulation. Annu Rev Nutr 29: 153-176, 2009.

18. Fukada T and Kambe T: Molecular and genetic features of zinc transporters in physiology and pathogenesis. Metallomics 3: 662-674, 2011.

19. Jeong J and Eide DJ: The SLC39 family of zinc transporters. Mo Aspects Med 34: 612-619, 2013.

20. Ibs KH and Rink L: Zinc-altered immune function. J Nutr 133 (Suppl 1): S1452-S1456, 2003.

21. Jansen J, Rosenkranz E, Overbeck S, Warmuth S, Mocchegiani E, Giacconi R, Weiskirchen R, Karges W and Rink L: Disturbed zinc homeostasis in diabetic patients by in vitro and in vivo analysis of insulinomimetic activity of zinc. J Nutr Biochem 23 : 1458-1466, 2012

22. Leone N, Courbon D, Ducimetiere P and Zureik M: Zinc, copper, and magnesium and risks for all-cause, cancer, and cardiovascular mortality. Epidemiology 17: 308-314, 2006.

23. Chimienti F, Devergnas S, Favier A and Seve M: Identification and cloning of a beta-cell-specific zinc transporter, ZnT-8, localized into insulin secretory granules. Diabetes 53: 2330-2337, 2004.

24. Li M, Zhang Y, Liu Z, et al: Aberrant expression of zinc transporter ZIP4 (SLC39A4) significantly contributes to human pancreatic cancer pathogenesis and progression. Proc Natl Acad Sci USA 104: 18636-18641, 2007.
25. Scotto M, A fonso G, Larger E, et al: Zinc transporter (ZnT) $8_{186-194}$ is an immunodominant CD8 ${ }^{+} \mathrm{T}$ cell epitope in HLA-A2 $2^{+}$type 1 diabetic patients. Diabetologia 55: 2026-2031, 2012.

26. Alam S and Kelleher SL: Cellular mechanisms of zinc dysregulation: a perspective on zinc homeostasis as an etiological factor in the development and progression of breast cancer. Nutrients 4 : 875-903, 2012.

27. Ebara M, Fukuda H, Hatano R, Saisho H, Nagato Y, Suzuki K, Nakajima K, Yukawa M, Kondo F, Nakayama A and Sakurai H: Relationship between copper, zinc and metallothionein in hepatocellular carcinoma and its surrounding parenchyma. J Hepatol 33: 415-422, 2000.

28. Franklin RB, Levy BA, Zou J, Hanna N, Desouki MM, Bagasra O, Johnson LA and Costello LC: ZIP14 zinc transporter downregulation and zinc depletion in the development and progression of hepatocellular cancer. J Gastrointest Cancer 43: 249-257, 2011.

29. Aydemir TB, Sitren HS and Cousins RJ: The zinc transporter Zip14 influences c-Met phosphorylation and hepatocyte proliferation during liver regeneration in mice. Gastroenterology 142: 1536-1546, 2012.

30. Reinhold D, Bank U, Buhling F, Lendeckel U, Faust J, Neubert K and Ansorge S: Inhibitors of dipeptidyl peptidase IV induce secretion of transforming growth factor-beta 1 in PWM-stimulated PBMC and T cells. Immunology 91: 354-360, 1997.

31. Raab AK, Monkemuller K, Kandulski A, Weber E, Malfertheiner P and Wex T: Expression pattern of cathepsin W isoforms in peripheral blood and gastroesophageal mucosa of patients with gastroesophageal reflux disease. Biol Chem 392: 1167-1172, 2011.

32. Overbeck S, Uciechowski P, Ackland ML, Ford D and Rink L: Intracellular zinc homeostasis in leukocyte subsets is regulated by different expression of zinc exporters ZnT-1 to ZnT-9. J Leukoc Biol 83: 368-380, 2008.

33. Peters JL, Dufner-Beattie J, Xu W, Geiser J, Lahner B, Salt DE and Andrews GK: Targeting of the mouse Slc39a2 (Zip2) gene reveals highly cell-specific patterns of expression, and unique functions in zinc, iron, and calcium homeostasis. Genesis 45: 339-352, 2007.

34. Kitamura H, Morikawa H, Kamon H, Iguchi M, Hojyo S, Fukada T, Yamashita S, Kaisho T, Akira S, Murakami M and Hirano T: Toll-like receptor-mediated regulation of zinc homeostasis influences dendritic cell function. Nat Immunol 7: 971-977, 2006.

35. Wang ZY and Dahlstrom A: Axonal transport of zinc transporter 3 and zinc containing organelles in the rodent adrenergic system. Neurochem Res 33: 2472-2479, 2008.

36. Murphy BL, Hofacer RD, Faulkner CN, Loepke AW and Danzer SC: Abnormalities of granule cell dendritic structure are a prominent feature of the intrahippocampal kainic acid model of epilepsy despite reduced postinjury neurogenesis. Epilepsia 53: 908-921, 2012.

37. John E, Laskow TC, Buchser WJ, Pitt BR, Basse PH Butterfield LH, Kalinski P and Lotze MT: Zinc in innate and adaptive tumor immunity. J Transl Med 8: 118, 2010. 